\title{
Loss of range of motion of the hip joint: a hypothesis for etiology of sports hernia
}

\author{
Rohit Rambani \\ Roger Hackney
}

Leeds Teaching Hospital NHS Trust Leeds, Sheffield, UK

Corresponding author:

Rohit Rambani

Leeds Teaching Hospital NHS Trust Leeds

82 Mackenzie Crescent

Sheffield S35 1US, UK

E-mail: rohit@rambani.com

\section{Summary}

Background: sports hernia is a well-recognized cause of groin pain in athletes involved in sports, especially football and rugby. Loss of range of motion of the hip joint is a possible contributory factor to stress across the symphysis pubis leading to the instability.

Methods: twenty-five athletes presenting with sports hernia were matched to age, sex, physical/sports activity and co-morbidities with twenty-five athletes without sports hernia. The range of movement of both the hips was compared in athletes of both the groups. Results: there was marked restriction of internal rotation with the hip flexed to 90 degrees (average 17 degrees) and external rotation (average 26 degrees) in sports hernia group compared to the control group. Other movements of the hip were comparable in both the groups.

Conclusion: the study highlights observation of limitation of hip rotation with the hip flexed to 90 degrees as a possible factor in the aetiology of sports hernia. There may be an association with other pathologies of the hip such as impingement that requires further investigation. Though this study has its limitation in being a small number and a case control study, it does helps in understanding the possible mechanism of development of this condition.

KEY WORDS: sports hernia, groin pain, hip movements, osteitis pubis.

\section{Introduction}

Hernia has been described as the condition of a weakened posterior wall of the inguinal canal (trans- versalis fascia), resulting in chronic activity-related pain in the groin and surrounding structures. Athletic pubalgia $^{1}$, sportsman's hernia ${ }^{2}$, incipient hernia ${ }^{3}$, osteitis pubis ${ }^{1}$, Gilmore's groin ${ }^{4}$, hockey groin syndrome $^{5}$ and Ashby's inguinal ligament enthesopathy ${ }^{6}$ are some of the terms that have complete or partial overlap with sports hernia.

Osteitis pubis is a separate recognised condition, but has been commonly associated with the obscure groin pain ${ }^{7}$ and misinterpreted as sports hernia.

Having said that, hernia is not an appropriate term for this condition, since, in many cases, an actual hernia is not seen 8,9 . A hernia is defined when an internal part of the body pushes through a weakness in the muscle or surrounding tissue wall. Hackney first coined the term sports hernia because of the similar pathology as in inguinal hernia ${ }^{1}$.

Several theories exist in the literature regarding the cause of sports hernia $7,10-14$; most theories implicating the overuse syndrome. According to one theory, hip abduction, adduction, and flexion-extension with the resultant pelvic motion produce a shearing force across the pubic symphysis, leading to stress on the inguinal wall musculature perpendicular to the fibres of the fascia and muscle ${ }^{3,15}$. Pull from the adductor musculature against a fixed lower extremity can cause significant shear forces across the hemipelvis ${ }^{10}$. Subsequent attenuation or tearing of the transversalis fascia or conjoined tendon has also been suggested as the source of pain ${ }^{1}$. Other studies have reported abnormalities at the insertion of the rectus abdominis muscle ${ }^{5,16-18}$.

The possible aetiologies for groin pain are vast, cover a wide range of physiologic systems and medical subspecialties, and require a thorough history and examination. Insidious onset of unilateral groin pain is the most commonly reported symptom with injuries of this type.

Though the actual cause of sports hernia is unknown various theories have been proposed but none of them have been proven. We propose that loss of range of motion of the hip is a significant factor in the etiology of this condition.

\section{Material and methods}

\section{The study}

Twenty-five athletes presenting with sportshernia were prospectively matched to age, sex, sports, 
physical activity and co-morbidities with twenty-five athletes without sports hernia (control group) over a one-year period were included in the study. The range of movement of both the hips was compared in athletes of both the groups. The results were compared in the two groups. The hospital audit and ethics committee approved the study.

\section{The control group}

The control population consisted of volunteers sampled from fracture clinic who had presented with upper limb injuries. To be included in the analysis, volunteers confirmed they had no prior history of groin pain or any previous hip or knee surgery. The control group was matched with the study group based on age, sex, co-morbidity, sports and physical activity (Tab. 1).

\section{The study group}

25 consecutive patients presenting to our clinic with sports hernia were recruited in the study. Fifteen patients had bilateral symptoms where as ten patients had unilateral symptoms. All patients were investigated to confirm that they do not have any inguinal hernia or any other known cause of groin pain. These include ultrasound examination; x-ray examination and $\mathrm{MRI}$ to rule out femoral acetabular impingement. Patients with cam, pincer or combined type of impingement on $\mathrm{x}$-rays/MRI were excluded from the study. All patients had started with insidious onset of unilateral groin pain.

Two assessors checked the range of movements of both the hips in the two groups using a digital goniometer. Three reading were taken by each of the assessor to avoid inter-observer and intra-observer error. The average of each of the reading was finally accepted. The results of range of movement were compared in the two groups for flexion, extension, abduction, adduction, internal rotation and external rotation with the patient supine and prone. The patients were asked to do the movements actively first explaining them what to do and then passive range of movement was checked to see if there is any increase in the range of movement.

Table 1. Matched sports hernia group and control group.

\begin{tabular}{lll}
\hline & Sports hernia & Control group \\
\hline Number & 25 & 25 \\
Age & $23.2(17-35)$ & $22.8(16-34)$ \\
Sex & Males 18 & Males 18 \\
& Females 7 & Females 7 \\
Comorbidities & Asthma 3 & Asthma 2 \\
& Diabetes 1 & Diabetes 1 \\
\hline
\end{tabular}

\section{Operative findings}

Operative findings included weakening and thinning of the conjoined tendon of transversalis and internal oblique muscles. The weakness amounts to a direct hernia. With a short duration of symptoms the defect seems to be more to the medial end of the inguinal canal. The repair tightens up the weaknesses, drawing down good tissue to strengthen the attenuated tissues. The surgical technique used does not seem to matter providing tension is restored to the muscles of the posterior wall of the inguinal canal.

All patients who underwent surgical treatment were assessed at one year after the surgery to compare their range of movements preoperatively and post operatively.

\section{Results}

We found significant differences in restriction of internal and external rotation in the sports hernia group when compared to their corresponding age-gender matched control. Statistical analysis was done using SPSS ver 21 (IBM, New York, USA).

There was marked restriction of internal rotation with the hip flexed (average 17.4 degrees) and external rotation (average 26.2 degrees) in sports hernia group compared to the control group. This was statistically significant using paired t test ( $p$ value 0.03 ). Other movements of the hip were comparable in both the groups (Tab. 2).

Patients with unilateral symptoms had decrease of internal rotation and external rotation by 20 degrees in the affected side compared to the unaffected side.

There was a gradual improvement of all movements of the hip in patients who underwent surgery at one year and was compared to the control group. The results were statistically significant for internal rotation of the hip using paired t-test ( $p$ value 0.02 ) (Tab. 3 ).

\section{Discussion}

Our study highlights that the restriction of rotation of the hips can be a pre-disposing factor in the pathogenesis of the sports hernia. There was marked restriction of internal and external rotation in the study

Table 2. Range of hip movements in the control and the study group.

\begin{tabular}{lll}
\hline Movements & $\begin{array}{l}\text { Study Group } \\
\text { (Range) Affected } \\
\text { side }\end{array}$ & $\begin{array}{l}\text { Control group } \\
\text { (range) }\end{array}$ \\
\hline Flexion & $122.30(110-130)$ & $122.20(112-129)$ \\
Extension & $10.30(8-14)$ & $11.40(9-16)$ \\
Internal Rotation & $\mathbf{1 7 . 4 0}(10-23)$ & $\mathbf{4 0 . 9 0}(37-45)$ \\
External Rotation & $\mathbf{2 6 . 2 0 ( 2 3 - 2 9 )}$ & $\mathbf{4 5 . 1 0}(42-55)$ \\
Abduction & $35.20(30-39)$ & $35.90(33-42)$ \\
Adduction & $27.10(24-29)$ & $26.20(23-31)$ \\
\hline
\end{tabular}


Table 3. Range of movement in the Study group pre and 1-year post surgery.

\begin{tabular}{lll}
\hline Movements & Pre surgery & $\begin{array}{l}\text { 1 year post } \\
\text { surgery }\end{array}$ \\
\hline Flexion & $122.30(110-130)$ & $1250(110-133)$ \\
Extension & $10.30(8-14)$ & $13.20(9.2-15.8)$ \\
Internal Rotation & $\mathbf{1 7 . 4 0}(10-23)$ & $38.20(34-43)$ \\
External Rotation & $\mathbf{2 6 . 2 0}(23-29)$ & $39.40(35-45)$ \\
Abduction & $35.20(30-39)$ & $36.30(32-40)$ \\
Adduction & $27.10(24-29)$ & $28.20(25-30)$ \\
\hline
\end{tabular}

group compared to the control group. Patients with unilateral symptoms had decrease rotation in the affected side compared to the unaffected side.

Lacroix et al. ${ }^{5}$ believed that the abnormality existed in the external oblique muscle and aponeurosis. Another study suggested entrapment of the genital branches of the ilioinguinal or genitofemoral nerves may be the source of pain ${ }^{16}$. Young adult soccer ${ }^{1,2,4,10,19-22}$ and rugby $1,11,18,21,23$ players have been reported to be the most frequent victims of sport hernia according to vast majority of published studies and review articles. Runners $1,8,10,11,22,24$ and American football players $^{2,24,25}$ are also known to suffer from this injury.

Some groin injuries are effectively treated by non-surgical treatment. Conventional physiotherapy has little to offer. Patients report a long-term failure of conservative treatment. These included stretching and strengthening exercises from physiotherapists in addition to electrical modalities. Local anaesthetic and steroid injections provide no lasting relief, if at all.

Rest settles the pain, but it returns rapidly on resuming sport. The average duration of symptoms to presentation averaged 20 months with a range of 6 weeks to 5 years. Excellent results can be achieved with surgical repair, over $80 \%$ returning to competition and all patients reporting improvement.

An alternative theory is that it is simply a chronic stretching of the posterior inguinal wall due to the excess demands of sport ${ }^{3}$. The condition is rare amongst females, probably less than $2 \%{ }^{1}$. The history is similar to the male, but the examination is more difficult. The painful cough impulse can be detected as easily in a thin athletic person, but a small amount of subcutaneous fat can obscure the impression of a bulge.

It is important to understand that loss of internal rotation can be one of the factors predisposing to the development of sports hernia and more work can be done at the physiotherapy level to identify these patients and work on improving their range of movement. Restriction of rotation of hip as a causative factor for sports hernia has never been reported in the literature. Factors to improve rotations of the hip in highlevel athletes can be used to decrease the incidence of sports hernia. We propose athletes should be checked for rotation of the hips and specific rehabilitation targeted at improved rotation might be helpful in treating this condition.

The authors understand the limitations of the study having a small number in the two groups but it still high- lights the importance of limitation of hip rotation as a causative factor for the pathogenesis of sports hernia.

\section{Conclusion}

Sports hernia is a recognised condition and various hypothesis has been proposed ${ }^{16,18,21,26}$. We propose a hypothesis and possible remedy so that this condition can be avoided in athletes with predisposing factors $^{12,23}$. The study gives a comprehensive review of the sports hernia and proposes a hypothesis for the cause of sports hernia along with treatment options. This hypothesis has never previously been described in the literature. The study highlights the importance of looking for restricted range of hip rotation in patients with symptoms suggestive of sports hernia and targeted physiotherapy to improve rotation in helping to resolve the symptoms.

\section{References}

1. Hackney RG. The sports hernia: a cause of chronic groin pain British journal of sports medicine. 1993;27:58-62.

2. Kemp S, Batt ME. The 'sports hernia': a common cause of groin pain. The Physician and sportsmedicine. 1998;26:36-44.

3. Braun $\mathrm{P}$, Jensen $\mathrm{S}$. Hip pain - a focus on the sporting population. Australian family physician. 2007;36:406-408.

4. Ekberg O, Persson NH, Abrahamsson PA, Westlin NE, Lilja B. Longstanding groin pain in athletes. A multidisciplinary approach. Sports Med. 1988; 6:56-61.

5. Lacroix VJ, Kinnear DG, Mulder DS, Brown RA. Lower abdominal pain syndrome in national hockey league players: a report of 11 cases. Clinical journal of sport medicine: official journal of the Canadian Academy of Sport Medicine. 1998;8:59.

6. Ashby EC. Chronic obscure groin pain is commonly caused by enthesopathy: 'tennis elbow' of the groin. The British journal of surgery. 1994;81:1632-1634.

7. Smedberg SG, Broome AE, Elmer O, Gullmo A. Herniography in the diagnosis of obscure groin pain. Acta chirurgica Scandinavica. 1985;151:663-667.

8. Meyers WC, Foley DP, Garrett WE, Lohnes JH, Mandlebaum BR. Management of severe lower abdominal or inguinal pain in high-performance athletes. PAIN (Performing Athletes with Abdominal or Inguinal Neuromuscular Pain Study Group). The American journal of sports medicine. 2000;28:2-8.

9. Simonet WT, Saylor HL 3rd, Sim L. Abdominal wall muscle tears in hockey players. International journal of sports medicine. 1995;16:126-128.

10. Malycha $P$, Lovell $G$. Inguinal surgery in athletes with chronic groin pain: the 'sportsman's' hernia. The Australian and New Zealand journal of surgery. 1992; 62:123-125.

11. Polglase AL, Frydman GM, Farmer KC. Inguinal surgery for debilitating chronic groin pain in athletes. The Medical journa of Australia. 1991;155:674-677.

12. Wiley JJ. Traumatic osteitis pubis: the gracilis syndrome. The American journal of sports medicine. 1983;11:360-363.

13. Williams JG. Limitation of hip joint movement as a factor in traumatic osteitis pubis. British journal of sports medicine. 1978:12:129-133.

14. Puranen J, Orava S. The hamstring syndrome. A new diagnosis of gluteal sciatic pain. The American journal of sports medicine. 1988;16:517-521.

15. Padulo J, Oliva F, Frizziero A, Maffulli N. Muscles, Ligaments 
and Tendons Journal. Basic principles and recommendations in clinical and field science research. MLTJ. 2013;4:250-252.

16. Akita K, Niga S, Yamato Y, Muneta T, Sato T. Anatomic basis of chronic groin pain with special reference to sports hernia. Surgical and radiologic anatomy: SRA. 1999;21:1-5.

17. Kumar A, Doran J, Batt ME, Nguyen-Van-Tam JS, Beckingham IJ. Results of inguinal canal repair in athletes with sports hernia. Journal of the Royal College of Surgeons of Edinburgh. 2002;47:561-565.

18. Taylor DC, Meyers WC, Moylan JA, Lohnes J, Bassett FH, Garrett WE Jr. Abdominal musculature abnormalities as a cause of groin pain in athletes. Inguinal hernias and pubalgia. The American journal of sports medicine. 1991;19:239242.

19. Ingoldby CJ. Laparoscopic and conventional repair of groin disruption in sportsmen. The British journal of surgery. 1997; 84:213-215.

20. Kesek P, Ekberg O, Westlin N. Herniographic findings in athletes with unclear groin pain. Acta Radiol. 2002;43:603-608

21. Orchard JW, Read JW, Neophyton J, Garlick D. Groin pain associated with ultrasound finding of inguinal canal posterior wall deficiency in Australian Rules footballers. British journal of sports medicine. 1998;32: 134-139.

22. Srinivasan A, Schuricht A. Long-term follow-up of laparoscopic preperitoneal hernia repair in professional athletes. Journal of laparoendoscopic \& advanced surgical techniques Part A. 2002;12:101-106.

23. Kluin J, den Hoed PT, van Linschoten R, JC IJ, van Steensel CJ. Endoscopic evaluation and treatment of groin pain in the athlete. The American journal of sports medicine. 2004;32 944-949.

24. Susmallian S, Ezri T, Elis M, Warters R, Charuzi I, Muggia-Sullam M. Laparoscopic repair of "sportsman's hernia" in soccer players as treatment of chronic inguinal pain. Medical science monitor: international medical journal of experimental and clinical research. 2004;10:CR52-54.

25. Smedberg SG, Broome AE, Gullmo A, Roos H. Herniography in athletes with groin pain. American journal of surgery. 1985;149:378-382.

26. Eames NW, Deans GT, Lawson JT, Irwin ST. Herniography for occult hernia and groin pain. The British journal of surgery. 1994;81:1529-1530. 